\title{
Tenascin-C: an emerging prognostic biomarker in diabetes
}

\author{
Saori Yonebayashi", Kazuko Tajiri", Siqi Li, Akira Sato \\ Department of Cardiology, Faculty of Medicine, University of Tsukuba, Tsukuba, Ibaraki, Japan \\ \#These authors contributed equally to this work. \\ Correspondence to: Akira Sato, MD, PhD. Department of Cardiology, Faculty of Medicine, University of Tsukuba, 1-1-1 Tennodai, Tsukuba, Ibaraki \\ 305-8575, Japan. Email: asato@md.tsukuba.ac.jp. \\ Comment on: Gellen B, Thorin-Trescases N, Thorin E, et al. Serum tenascin-C is independently associated with increased major adverse \\ cardiovascular events and death in individuals with type 2 diabetes: a French prospective cohort. Diabetologia 2020;63:915-23.
}

Submitted Jun 04, 2020. Accepted for publication Jun 17, 2020.

doi: 10.21037/atm-2020-116

View this article at: http://dx.doi.org/10.21037/atm-2020-116

Diabetes has become one of the most pressing issues in the last few decades. The worldwide prevalence of diabetes has reached 380 million (1). Furthermore, cardiovascular disease (CVD) is the leading cause of death in diabetes patients (2). Therefore, cardiovascular $(\mathrm{CV})$ risk stratification is particularly important in diabetics and the search for new predictive biomarkers of $\mathrm{CV}$ disease is critical to find. A recent issue of Diabetologia, Gellen et al. (3) showed the association of serum concentration of tenascin-C (TNC), an extracellular matrix (ECM) glycoprotein, with allcause mortality and major adverse $\mathrm{CV}$ events (MACE). The investigators measured serum TNC concentrations from 1,321 type 2 diabetes patients and monitored them for 89 months. They reported that TNC concentrations were independently correlated with a higher risk of allcause death and MACE [composed of CV death, non-fatal myocardial infarction (MI), and non-fatal stroke]. Using TNC concentrations in addition to conventional risk factors, the prediction of the all-cause death and MACE risk improved modestly, but significantly.

TNC is a non-structural ECM expressed in the heart's early embryonic development, but it is not present in the normal adult myocardium (4). In tissue injury or active remodeling, its expression increases rapidly in a spatiotemporally restricted manner (4). It has a broad range of effects which include cell adhesion, motility, survival, proliferation, and differentiation in tissue morphogenesis and remodeling including the $\mathrm{CV}$ system [reviewed in $(5,6)]$. Recently, TNC is gaining attention as a regulator of inflammation through various molecular mechanisms [reviewed in (7)]. Animal models have greatly advanced our understanding of the molecular mechanisms of TNC involved in $\mathrm{CV}$ pathogenesis over the last two decades. Moreover, an increasing number of studies have reported the use of the serum TNC level as a biomarker for assessing disease activity and predicting the prognosis of patients with CVDs.

We previously reported that serum TNC concentrations were elevated in patients following acute $\mathrm{MI}$ and remained higher in patients with adverse ventricular remodeling (8). We also reported that serum TNC levels measured in patients on day 5 after admission for acute MI has a similar prognostic value to that of plasma BNP levels (9). Moreover, the combination of serum TNC and plasma BNP levels with established prognostic markers improved risk stratification for MACE and cardiac death (9). In the acute inflammatory phase of MI, TNC is exclusively localized in the border zone between intact myocardium and infarcted lesion, but becomes absent in the scar-formation stage (10-12). In our present study, TNC knockout (KO) mice were protected from ventricular adverse remodeling, with decreased inflammatory M1- and increased regulatory M2-macrophage infiltration detected in the TNC KO heart during the acute phase after MI (12). In vitro experiments showed that TNC promoted macrophages to shift to an M1 phenotype via Toll-like receptor 4, whereas under M2-altering conditions, TNC suppressed interferon regulatory factor 4 expression, resulting in inhibition of M2 polarization (12). Thus, it has been suggested that TNC accelerates adverse post-infarction remodeling by 
perturbing macrophage functions.

Several clinical studies have demonstrated the potential use of TNC for pathological evaluation and prognosis assessment in patients with heart failure $(13,14)$. In one study, cardiac pressure overload induced marked induction and interstitial deposition of TNC, which accelerated fibrosis, hypertrophy, and dysfunction in failing hearts $(15,16)$. In another study, the local production of TNC acted as a trigger for monocyte/macrophage recruitment and shifted them into a pro-inflammatory phenotype that exacerbated cardiac dysfunction $(16,17)$. In a model of myocarditis, we have previously shown that TNC worsens autoimmune myocarditis by inducing dendritic cell activation and T-helper 17 cell differentiation via Tolllike receptor 4 (18). Thus, these results suggest that TNC may act as an endogenous driver of innate immunity in the failing heart.

TNC has also been reported to be involved in the pathophysiology of aneurysmal and dissecting aortic lesions. In human and $\mathrm{CaCl}_{2}$-induced mouse abdominal aortic aneurisms, TNC expression levels were positively correlated with the expansion rate of the aneurismal diameter and the destruction of the aortic wall (19). However, in a mouse model of aortic stiffening, a known risk factor for acute aortic dissection, TNC protects the aorta from dissection, but not from aneurysmal formation and works as a stressinduced molecular inhibitor to maintain the aortic integrity under acute stress (20). We have previously reported that high serum TNC levels on admission is a predictor of high mortality within 30 days (21), whereas high serum TNC levels at 7 days after admission predicts a low risk of aortic enlargement during the chronic stage (22). These clinical data suggest that the role of TNC in the aorta is complex and alters depending on the state of the aorta that changes as time proceeds after aortic dissection. Further studies are needed to clarify the exact role of TNC in the progression of acute aortic dissection.

In the cohort study from Gellen et al. (3), higher TNC concentrations were associated with longer durations of diabetes. However, whether elevated TNC levels are a cause or a result of diabetes is still unknown. One possibility is that TNC directly activates signaling pathways that lead to diabetes. Alternatively, it is also possible that diabetic conditions could increase the amount of TNC. Finally, the defining question as to whether TNC is beneficial or detrimental in diabetes still remains unanswered. Further investigations are necessary to elucidate the potential role of $\mathrm{TNC}$ in diabetes as an etiological factor.

\section{Acknowledgments}

Funding: None.

\section{Footnote}

Provenance and Peer Review: This article was commissioned by the editorial office, Annals of Translational Medicine. The article did not undergo external peer review.

Conflicts of Interest: All authors have completed the ICMJE uniform disclosure form (available at http://dx.doi. org/10.21037/atm-2020-116). The authors have no conflicts of interest to declare.

Ethical Statement: The authors are accountable for all aspects of the work in ensuring that questions related to the accuracy or integrity of any part of the work are appropriately investigated and resolved.

Open Access Statement: This is an Open Access article distributed in accordance with the Creative Commons Attribution-NonCommercial-NoDerivs 4.0 International License (CC BY-NC-ND 4.0), which permits the noncommercial replication and distribution of the article with the strict proviso that no changes or edits are made and the original work is properly cited (including links to both the formal publication through the relevant DOI and the license). See: https://creativecommons.org/licenses/by-nc-nd/4.0/.

\section{References}

1. GBD 2016 Disease and Injury Incidence and Prevalence Collaborators. Global, regional, and national incidence, prevalence, and years lived with disability for 328 diseases and injuries for 195 countries, 1990-2016: a systematic analysis for the Global Burden of Disease Study 2016. Lancet 2017;390:1211-59.

2. Morrish NJ, Wang SL, Stevens LK, et al. Mortality and causes of death in the WHO multinational study of vascular disease in diabetes. Diabetologia 2001;44:S14-21.

3. Gellen B, Thorin-Trescases N, Thorin E, et al. Serum tenascin-C is independently associated with increased major adverse cardiovascular events and death in individuals with type 2 diabetes: a French prospective cohort. Diabetologia 2020;63:915-23.

4. Imanaka-Yoshida K, Yoshida T, Miyagawa-Tomita S. Tenascin-C in development and disease of blood vessels. 
Anat Rec (Hoboken) 2014;297:1747-57.

5. Midwood KS, Orend G. The role of tenascin-C in tissue injury and tumorigenesis. J Cell Commun Signal 2009;3:287-310.

6. Imanaka-Yoshida $\mathrm{K}$. Tenascin-C in cardiovascular tissue remodeling: from development to inflammation and repair. Circ J 2012;76:2513-20.

7. Marzeda AM, Midwood KS. Internal affairs: tenascin-C as a clinically relevant, endogenous driver of innate immunity. J Histochem Cytochem 2018;66:289-304.

8. Sato A, Aonuma K, Imanaka-Yoshida K, et al. Serum tenascin-C might be a novel predictor of left ventricular remodeling and prognosis after acute myocardial infarction. J Am Coll Cardiol 2006;47:2319-25.

9. Sato A, Hiroe M, Akiyama D, et al. Prognostic value of serum tenascin-C levels on long-term outcome after acute myocardial infarction. J Card Fail 2012;18:480-6.

10. Nishioka T, Onishi K, Shimojo N, et al. Tenascin-C may aggravate left ventricular remodeling and function after myocardial infarction in mice. Am J Physiol Heart Circ Physiol 2010;298:H1072-8.

11. Imanaka-Yoshida K, Hiroe M, Nishikawa T, et al. Tenascin-C modulates adhesion of cardiomyocytes to extracellular matrix during tissue remodeling after myocardial infarction. Lab Invest 2001;81:1015-24.

12. Kimura T, Tajiri K, Sato A, et al. Tenascin-C accelerates adverse ventricular remodelling after myocardial infarction by modulating macrophage polarization. Cardiovasc Res 2019;115:614-24.

13. Yokokawa T, Sugano Y, Nakayama T, et al. Significance of myocardial tenascin-C expression in left ventricular remodelling and long-term outcome in patients with dilated cardiomyopathy. Eur J Heart Fail 2016;18:375-85.

14. Hessel MHM, Bleeker GB, Bax JJ, et al. Reverse

Cite this article as: Yonebayashi S, Tajiri K, Li S, Sato A. Tenascin-C: an emerging prognostic biomarker in diabetes. Ann Transl Med 2020;8(24):1699. doi: 10.21037/atm-2020-116 ventricular remodelling after cardiac resynchronization therapy is associated with a reduction in serum tenascin- $\mathrm{C}$ and plasma matrix metalloproteinase-9 levels. Eur J Heart Fail 2007;9:1058-63.

15. Podesser BK, Kreibich M, Dzilic E, et al. Tenascin-C promotes chronic pressure overload-induced cardiac dysfunction, hypertrophy and myocardial fibrosis. J Hypertens 2018;36:847-56.

16. Abbadi D, Laroumanie F, Bizou M, et al. Local production of tenascin-C acts as a trigger for monocyte/macrophage recruitment that provokes cardiac dysfunction. Cardiovasc Res 2018;114:123-37.

17. Shimojo N, Hashizume R, Kanayama K, et al. Tenascin-C may accelerate cardiac fibrosis by activating macrophages via the integrin $\alpha \mathrm{V} \beta 3 /$ nuclear factor- $\kappa \mathrm{B} /$ interleukin- 6 axis novelty and significance. Hypertension 2015;66:757-66.

18. Machino-Ohtsuka T, Tajiri K, Kimura T, et al. Tenascin-C aggravates autoimmune myocarditis via dendritic cell activation and Th17 cell differentiation. J Am Heart Assoc 2014;3:e001052.

19. Kimura T, Yoshimura K, Aoki H, et al. Tenascin-C is expressed in abdominal aortic aneurysm tissue with an active degradation process. Pathol Int 2011;61:559-64.

20. Kimura T, Shiraishi K, Furusho A, et al. Tenascin C protects aorta from acute dissection in mice. Sci Rep 2014;4:4051.

21. Nozato T, Sato A, Hirose S, et al. Preliminary study of serum tenascin-C levels as a diagnostic or prognostic biomarker of type B acute aortic dissection. Int J Cardiol 2013;168:4267-9.

22. Nozato T, Sato A, Hikita H, et al. Impact of serum tenascin- $\mathrm{C}$ on the aortic healing process during the chronic stage of type B acute aortic dissection. Int J Cardiol 2015;191:97-9. 